\title{
An Urban Smart Growth Evaluation Method
}

\author{
Mingxuan Lu \\ School of Electrical and Electronic Engineering, North China Electric Power University, Baoding \\ 071000, China. \\ 2870525679@qq.com
}

Keywords: Urban Development, Smart Growth Evaluation, Fuzzy Analytical Hierarchy Process.

\begin{abstract}
As the world is rapidly urbanizing, the smart growth theory is widely applied into the urban development and is becoming a more and more important issue. The paper provides a method to evaluate the degree of the urban smart growth, which could give some instructions of making plans for urban development. Based on the 3E's sustainability (Economically prosperous, socially Equitable, and Environmentally Sustainable), ten principles of smart growth are classified into six aspects, named as growth patterns and trends, nature resources and environmental quality, transportation, affording house, fiscal dimensions, and survey of opinion leaders. Each aspect has several indicators in detail. Fuzzy analytic hierarchy process (FAHP) is used to determine the weight of the indicators in every aspect. It is similar to deal with the weight of six aspects in the metric. In order to analyze quantitatively, the indicators are graded roughly based on practical data.
\end{abstract}

\section{Introduction}

These days, the level of urbanization is getting higher and higher, and more and more people are moving to the city at the same time. The concept of "Smart Growth" was first proposed by American environmental scholars and urban planners. In 1996, USEPA organized a number of agencies to set up a network of organizations aimed at promoting the city's smart growth, put forward ten planning principles [3]: Mix land uses; Take advantage of compact building design; Create a range of housing opportunities and choices; Create walk able neighborhoods; Foster distinctive, attractive communities with a strong sense of place; Preserve open space, farmland, natural beauty, and critical environmental areas; Strengthen and direct development towards existing communities; Provide a variety of transportation choices; Make development decisions predictable, fair, and cost effective; From the principles listed above, we can find that growth is smart when it gives us great communities, with more choices and personal freedom, good return on public investment, greater opportunity across the community, a thriving natural environment, and a legacy we can be proud to leave our children and grandchildren. [2] After a long period of development, now Smart Growth has become a complete system of urban development.

\section{Urban Smart Growth Evaluation}

Most of the evaluation criteria of Smart Growth are qualitative analysis. However, an urban Smart Growth evaluation method needs determining to analyze quantitatively, which should consider the 3E's sustainability and the ten principles of Smart Growth. Considering the availability and reliability of data, six aspects and the fifteen indicators are extracted, and FAHP (fuzzy analytic hierarchy process) is used to measure metric of the success.

\subsection{Smart Growth Indicator System}

Based on the analysis of the impact of users on the transmission and distribution grid, a smart growth indicator system is constructed, which sums up the factors that affect the urban Smart growth in six aspects, growth patterns and trends, natural resources and environmental quality, transportation, affordable housing, finance, the leadership of the survey. 
'Mixed land use' and 'take advantage of compact building design' are classified as growth patterns and trend, which mainly includes growth of population, population density, population distribution and employment. These indicators influence the urban population growth pattern, urban concentration and centralization.

'Foster distinctive, attractive communities with a strong sense of place' and 'preserve open space, farmland, natural beauty, and critical environmental areas' are classified as nature resources and environmental quality, which mainly includes the variation of conservation area and agricultural Land. It shows the increasing of population caused the loss of resources and agricultural land.

'Provide a variety of transportation choices' is classified as transportation, which mainly includes variation of bus share, variation of bike/walk share, and the growth rate of congestion.

'Create walk-able neighborhoods', 'strengthen and direct development towards existing communities' and 'create a range of housing opportunities and choices' are classified as affording house.

'Make development decisions predictable, fair, and cost effective' are classified as fiscal dimension, which mainly includes growth of total income and the ratio of income and expenditure.

'Encourage community and stakeholder collaboration in development decisions' is classified as survey of opinion leaders, which mainly includes foresight of decisions, fairness of decisions and public participation.

The construction is as Figure1:

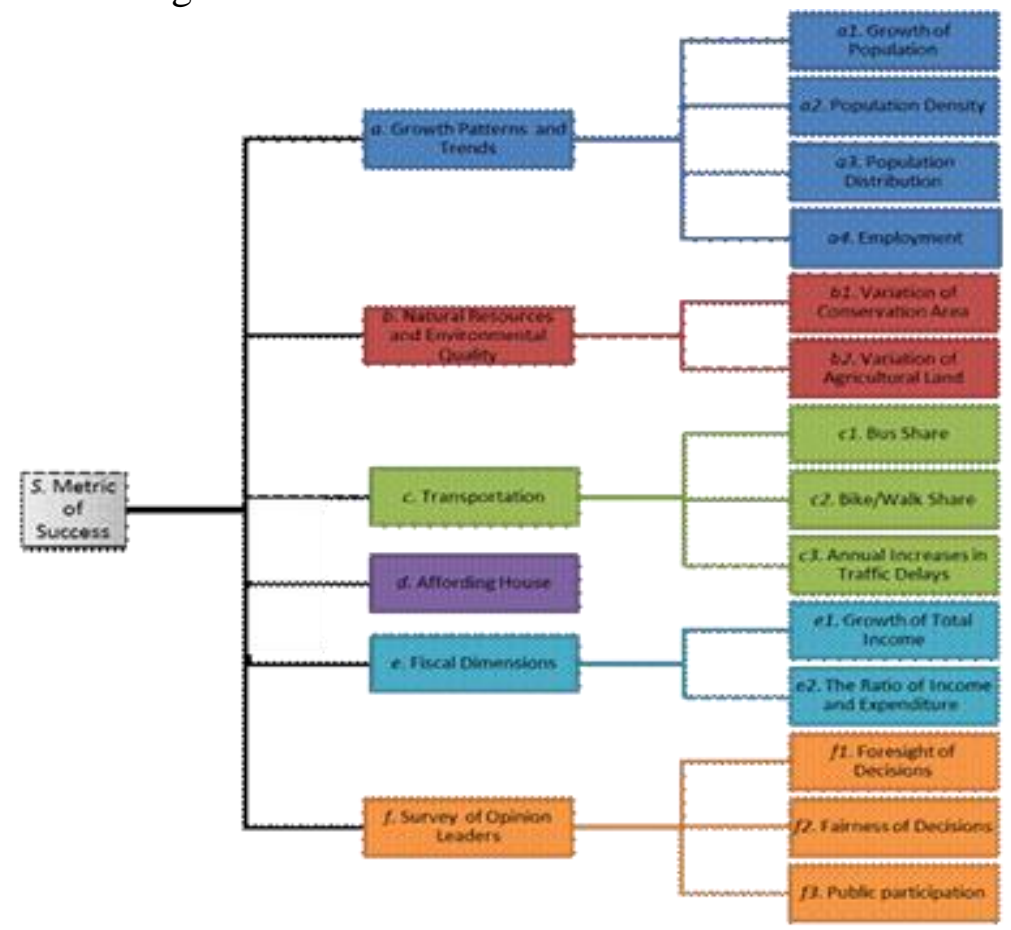

\subsection{FAHP}

Fig. 1 Two or more references

FAHP, which is more scientific, reasonable and practical than AHP (analytic hierarchy process), is used to determine the weight of each aspect and indicator. The main steps are as follows: [5]

a) Construct the precedence relation matrix.

Using the $0.1 \sim 0.9$ scale, establish the priority judgment matrix.

$F=\left(f_{i j}\right)_{n \times n}$

b) Transform the priority judgment matrix into the fuzzy consistent matrix.

$R=\left(r_{i j}\right)_{n \times n}$

$r_{i j}=\left(r_{i}-r_{j}\right) / 2 n+0.5$ 
$r_{i}=\sum_{j=1}^{n} f_{i j}, i=1,2, \cdots n$

Calculate the sort vector.

$$
W^{(0)}=\left[\frac{\sqrt[n]{\prod_{j=1}^{n} r_{1 j}}}{\sum_{i=1}^{n} \sqrt[n]{\prod_{j=1}^{n} r_{i j}}}, \frac{\sqrt[n]{\prod_{j=1}^{n} r_{2 j}}}{\sum_{i=1}^{n} \sqrt[n]{\prod_{j=1}^{n} r_{i j}}}, \cdots \frac{\sqrt[n]{\prod_{j=1}^{n} r_{n j}}}{\sum_{i=1}^{n} \sqrt[n]{\prod_{j=1}^{n} r_{i j}}}\right]^{T}
$$

\subsection{Weight and Equation}

The fuzzy consistent matrix of success degree:

$$
\begin{aligned}
R_{S} & =\left[\begin{array}{lllllll}
0.5000 & 0.5000 & 0.5333 & 0.5583 & 0.5083 & 0.6000 \\
0.5000 & 0.5000 & 0.5333 & 0.5583 & 0.5083 & 0.6000 \\
0.4667 & 0.4667 & 0.5000 & 0.5250 & 0.4750 & 0.5667 \\
0.4417 & 0.4417 & 0.4750 & 0.5000 & 0.4500 & 0.5417 \\
0.4917 & 0.4917 & 0.5250 & 0.5500 & 0.5000 & 0.5917 \\
0.4000 & 0.4000 & 0.4333 & 0.4583 & 0.4083 & 0.5000
\end{array}\right] \\
F_{S} & =\left[\begin{array}{lllll}
0.5 & 0.5 & 0.6 & 0.6 & 0.5 \\
0.5 & 0.5 & 0.6 & 0.6 & 0.5 \\
0.4 & 0.4 & 0.5 & 0.6 & 0.5 \\
0.4 & 0.4 & 0.4 & 0.5 & 0.4 \\
0.5 & 0.5 & 0.5 & 0.6 & 0.5
\end{array}\right]
\end{aligned}
$$

Based on the above method, we can get the equation:

$$
S=0.1887 a+0.1887 b+0.1650 c+0.1492 d+0.1825 e+0.1260 f
$$

Then adjust the range of success degree:

$$
S=\frac{S-0.1}{0.9-0.1}
$$

Similarly, we can get the equation of growth patterns and trend as formula 10, Equation of nature and environment is as formula, Equation of transportation is as formula (12), Equation of Fiscal Dimension is as formula (13), Equation of Survey of Opinion Leaders is as formula (14).

$$
\begin{aligned}
& a=0.3173 a_{1}+0.2118 a_{2}+0.2591 a_{3}+0.2118 a_{4} \\
& b=0.2 b_{1}+0.8 b_{2} \\
& c=0.2810 c_{1}+0.0711 c_{2}+0.6478 c_{3} \\
& e=0.5 e_{1}+0.5 e_{2} \\
& f=0.3548 f_{1}+0.3548 f_{2}+0.2903 f_{3}
\end{aligned}
$$

\section{Calculation Methods and Criteria}

In order to quantify the indicators, the indicators are divided into different levels. The criteria are as Table 1:

\section{Summary}

This paper discusses and establishes the evaluation system of the urban smart growth, which lay a foundation for the government to make plans for the urban development.

We summarize the 15 indicators that influence the urban development and construct a relatively objective evaluation index system. Then, FAHP is used to determine the weight of each 
indicator.Through the evaluation method, it is easy to measure the degree of the urban smart growth and make the next step and even long-term development plan for the urban.

Table 1 Criteria of the indicators

\begin{tabular}{|c|c|c|c|c|c|}
\hline $\begin{array}{l}\text { Grade } \\
\text { (Score) }\end{array}$ & $\begin{array}{c}1 \\
(0.1)\end{array}$ & $\begin{array}{c}2 \\
(0.3)\end{array}$ & $\begin{array}{c}3 \\
(0.5)\end{array}$ & $\begin{array}{c}4 \\
(0.7)\end{array}$ & $\begin{array}{c}5 \\
(0.9)\end{array}$ \\
\hline Growth of population (\%) & $<0.2$ & $0.2 \sim 0.5$ & $0.5 \sim 1.5$ & $1.5 \sim 2.5$ & $\geq 2.5$ \\
\hline $\begin{array}{l}\text { Population density } \\
\text { (person/acre) }\end{array}$ & $<500$ & $\begin{array}{c}500 \\
\sim \\
3000\end{array}$ & $\begin{array}{c}3000 \\
\sim \\
10000\end{array}$ & $\begin{array}{c}10000 \\
\sim \\
50000\end{array}$ & $\geq 50000$ \\
\hline $\begin{array}{c}\text { Variation of population } \\
\text { distribution }\end{array}$ & $0 \sim 0.2$ & $0.2 \sim 0.4$ & $0.4 \sim 0.55$ & $0.55 \sim 0.75$ & $0.75 \sim 1$ \\
\hline Growth of employment (\%) & $<0.5$ & $0.5 \sim 1.5$ & $1.5 \sim 3$ & $3 \sim 3.5$ & $\geq 3.5$ \\
\hline $\begin{array}{l}\text { Variation of conservation area } \\
\text { (acre/person) }\end{array}$ & $<-1$ & $-1 \sim-0.8$ & $-0.8 \sim-0.6$ & $-0.6 \sim-0.3$ & $\geq-0.3$ \\
\hline $\begin{array}{l}\text { Variation of agricultural Land } \\
\text { (acre/person) }\end{array}$ & $<-1$ & $-1 \sim-0.7$ & $-0.7 \sim-0.5$ & $-0.5 \sim-0.3$ & $\geq-0.3$ \\
\hline Variation of bus share (\%) & $<-2.5$ & $-2.5 \sim-0.5$ & $0 \sim 0.5$ & $0.5 \sim 2.5$ & $\geq 2.5$ \\
\hline Variation of bike/walk share (\%) & $<-2.5$ & $-2.5 \sim-0.5$ & $-0.5 \sim 0.5$ & $0.5 \sim 2.5$ & $\geq 2.5$ \\
\hline The growth rate of congestion & Very fast & Fast & Zero & Slow & Very slow \\
\hline Affording house (\%) & $0 \sim 40$ & $40 \sim 70$ & $70 \sim 100$ & $100 \sim 140$ & $\geq 140$ \\
\hline Growth of total income (\%) & $<2$ & $2 \sim 5$ & $5 \sim 7.5$ & $7.5 \sim 10$ & $\geq 10$ \\
\hline $\begin{array}{c}\text { The ratio of income and } \\
\text { expenditure }\end{array}$ & $\begin{array}{l}<0.6 \\
>1.67 \\
\end{array}$ & $\begin{array}{c}0.6 \sim 0.7 \\
1.42 \sim 1.67\end{array}$ & $\begin{array}{c}0.7 \sim 0.8 \\
1.25 \sim 1.42 \\
\end{array}$ & $\begin{array}{c}0.8 \sim 0.9 \\
1.11 \sim 1,25 \\
\end{array}$ & $0.9 \sim 1.11$ \\
\hline Foresight of decisions & Bad & General & Good & Very good & Excellent \\
\hline Fairness of decisions & $\mathrm{Bad}$ & General & Good & Very good & Excellent \\
\hline Public participation & Bad & General & Good & Very good & Excellent \\
\hline
\end{tabular}

\section{References}

[1]. World Urbanization Prospects United Nations. 2014. https:// esa.un. org/unpd/ wup/ Publications /Files/WUP2014-Highlights.pdf

[2]. EPA, "This is Smart Growth." 2016 https://www.epa.gov/smartgrowth/smart-growth-publication

[3]. EPA, "Smart Growth: A Guide to Developing and Implementing Greenhouse Gas Reductions Programs."

[4]. Canfei, Zou Peisi, Yin Wei. Smart growth policy evaluation (translation) [J]. Xinjiang agricultural science, 2011 (7): 1371-1371.

[5]. Li H. Matlab implementation of fuzzy analytic hierarchy process [J]. Silicon Valley, 2009 (17): $8+44$. 